\title{
Transdisciplinaridade e tecnologia: projeto de descarte de pilhas e baterias
}

\author{
Transdiciplinarity and technology: design of discharge of stacks and batteries
}

\author{
Shitsuka, R'; Teixeira, R.L.P²; Gouveia, L3 ; Silva, P.C.D ${ }^{4}$ \\ 1,2,4 Universidade Federal de Itajubá, Itabira, MG, Brasil. \\ ${ }^{3}$ Universidade do Estado de Minas Gerais, João Monlevade, MG, Brasil.
}

rshitsuka@uol.com.br

\begin{abstract}
RESUMO
O ensino de ciências é uma das áreas mais importantes para a formação de pessoas preparadas para lidar com os avanços da tecnologia, da pós-modernidade e da cidadania, e, para tanto, tornase interessante atrair jovens para esse saber. No Brasil existe um certo "desencanto" dos estudantes em relação às licenciaturas em ciências e matemática, e tornou-se um desafio para os autores buscarem formas de atrai-los para essas licenciaturas. Considerou-se, como forma de se trabalhar esse desencantamento, motivar os estudantes ao abordar temas como a cidadania e a transdisciplinaridade das ciências, e de que há axiomas comuns às ciências como um todo ou a um conjunto de disciplinas. Este estudo visa, assim, apresentar um projeto cidadão e transdisciplinar concebido para o incentivo aos jovens às carreiras de ensino de ciências. Realizou-se, portanto, um relato de caso de um projeto transdisciplinar realizado no Município de Itabira - MG voltado para a Semana Nacional de Ciência e Tecnologia. Os resultados dos trabalhos transdisciplinares executados mostraram que houve um aumento na motivação dos estudantes para carreiras docentes na área da ciência e tecnologia.
\end{abstract}

Palavras-chave: Ensino de ciências, Ensino por projetos, Complexidade, Divulgação científica, Licenciatura em ciências.

\begin{abstract}
Science education is one of the most important areas for the formation of people prepared to deal with advances in technology, postmodernity and citizenship. To this end, it is interesting to attract young people to this important area of knowledge. In Brazil there is a certain "disenchantment" of students about science and mathematics degrees and it has become a challenge for authors to seek ways to attract students to teaching in this area. It is considered as a way of working this disenchanting and motivating students is to stimulate them in understanding the sciences, what citizenship means and that there are axioms common to the sciences with all or a set of disciplines, the so-called transdiciplinarity. This study aims to present a transdisciplinary project aimed at encouraging young people to careers in science. This is a case report of a transdisciplinary project carried out in the city of Itabira focused on the National Week of Science and Technology. The results of the transdisciplinary work performed mentioned showed that there was a development of motivation in students in pursuing teaching careers in science and technology.
\end{abstract}

Keywords: Science education, Projects for education, Complexity, Scientific disclosure, Bachelor of Science. 


\section{INTRODUÇÃO}

O desenvolvimento e o futuro dos países dependem da boa formação na educação básica, em que se pode trabalhar o incentivo para a formação de cidadãos responsáveis e que se interessem em trabalhar com as ciências e tecnologias de modo transdisciplinar.

A transdisciplinaridade implica axiomas comuns a um conjunto de disciplinas e um encontro entre várias epistemologias. Conforme a Declaração de Veneza da Unesco e da intervenção de Basarab Nicolescu, existe também a possibilidade de uma transdisciplinaridade geral que consistiria em encontrar uma axiomática comum entre ciência, arte, filosofia e tradições sapienciais. A transdisciplinaridade é uma forma de abordagem holística intelectual, porém holística não é só transdisciplinar, pois esta baseia-se somente na visão duma experiência, enquanto a transdisciplinaridade abrangeria as ligações no interior de um sistema total (WEIL, 1993). Pela abordagem de um sistema total, a transdiciplinaridade também se distingue da multidisciplinaridade ou pluridisciplinaridade, pois ambas tratam de um objeto por várias disciplinas, podendo ou não ser estas integradas (RODRIGUES, 2000; SANTOS, 2019).

A forma de atuar da transdisciplinaridade é fomentando o protagonismo do estudante nos "saberes e fazeres" para uma educação holística sobre a educação (PINTO; FERREIRA, 2019). Este protagonismo estimula, motiva e instiga o estudante (GONÇALO; DE SOUZA; ANDRADE, 2019; FREITAS, 2019; MARCUZZO, 2019; SCHWARTZ, 2019). Trabalhos educacionais utilizando atividades de extensão transdisciplinares são instrumentos que podem levar a esta motivação, por exemplo a motivação dos estudantes da educação fundamental para carreiras de licenciatura (GUIMARÃES; BZUNECK; SANCHES, 2002; BERNARDES; IACHEL; SCALVI, 2008; WEBER; VIEIRA, 2019). O resultado desses trabalhos educacionais ocorrerá anos à frente, quando os estudantes da educação fundamental de hoje estiverem escolhendo suas carreiras ao final do ensino médio.

$\mathrm{Na}$ atualidade, há uma diminuição na procura pelas carreiras científicas nos vestibulares e processos seletivos das universidades, o que torna necessário um trabalho junto aos jovens mostrando a importância de um maior entendimento e comunicação dos aspectos conceituais entre múltiplas disciplinas para o conhecimento e o saber.

Os estudantes atuais estão desestimulados em relação às carreiras científicas e às licenciaturas em ciências (VIANA, 2014.). É importante que se trabalhe o incentivo aos jovens em relação às carreiras em ciências. Uma forma de trabalhar a transdiciplinaridade 
em sala de aula é através de estudos dos problemas ambientais. E, para que isso ocorra, é preciso que a ciência faça sentido na vida das pessoas (CASSINI; LISINGEN; GIRALDI, 2011). É importante trabalhar assuntos e temas interessantes para os estudantes, de preferência de temas atuais que afetam suas vidas e sociedades. E este é o caso dos temas relacionados ao meio ambiente e à sustentabilidade.

Os recursos naturais no Planeta Terra são limitados e é preciso saber utilizá-los com sabedoria para que não venham faltar no futuro. Uma das questões que aflige a sociedade é a relacionada ao descarte de pilhas e baterias (geradores elétricos químicos), que são necessárias, porém podem trazer riscos ambientais.

O objetivo deste trabalho é apresentar um projeto transdisciplinar realizado com estudantes de um colégio do Município de Itabira com relação ao uso e descarte de pilhas e baterias na escola. Este projeto teve como finalidade incentivá-los para a docência em ciências, trabalhar a formação cidadã e o respeito às diferenças e conscientizá-los em relação às possibilidades da economia solidária e a necessidade de se preservar o meio ambiente.

Algumas ações políticas e educacionais relacionadas à proposição de um projeto de lei enfocando a gestão de pilhas e baterias foram apresentadas no Parlamento Jovem de Rio Claro-SP (RUIZ; CHRISTOFOLETTI; RUIZ; Da SILVA, 2012), estas ações vêm ao encontro do proposto pela Política Nacional de Resíduos Sólidos (PRNS, Lei 12.305, de 2010).

Nas linhas seguintes, abordam-se em ordem e sequência os itens: "Pilhas e baterias e a questão ambiental", em que é tratada a questão do descarte inadequado e as consequências ambientais deste tipo de agressão ao ambiente. A seguir é abordada a questão da "Aprendizagem sobre o ambiente e a cidadania apoiados na autonomia e na transdisciplinaridade", em que se aborda a necessidade do aprendizado e de que forma isso pode ocorrer.

\subsection{Pilhas e baterias e a questão ambiental}

A sociedade precisa de energia para movimentar e fazer funcionar diversos tipos de aparelhos eletroeletrônicos, principalmente os dispositivos móveis necessitam de pilhas e baterias que facilitem a movimentação.

Muitas pilhas pequenas funcionam à base de mercúrio. Este é o caso de baterias tipo botão que são utilizadas em relógios de pulso, aparelhos de surdez e em algumas 
câmeras fotográficas. A maioria dessas é considerada perigosa para a saúde e para o ambiente. Em alguns países, tais baterias, quando exauridas, são devolvidas às lojas onde foram compradas, garantindo a aplicação de um importante instrumento da responsabilidade compartilhada pelo ciclo de vida dos produtos, e que se chama logística reversa.

A logística reversa é o processo de planejamento, implantação e controle dos custos, dos fluxos de matérias primas, produtos em estoque e acabados, bem como a informação relacionada, desde o ponto de consumo até onde o material é reprocessado, com o objetivo de recuperar valor ou realizar a disposição final adequada do produto (SHIBAO; MORI; SANTOS, 2010).

Pelo emprego da logística reversa, as baterias usadas de veículos são deixadas nos postos de gasolina ou pontos de coleta. Esses dispositivos são nocivos ao meio ambiente de modo semelhante aos geradores elétricos químicos de níquel-cádmio utilizadas em aparelhos recarregáveis, como é o caso de celulares, eletrodomésticos portáteis, brinquedos, notebooks, tablets, escovas de dentes elétricas, barbeadores, lanternas de emergência e etc. (REIDLER; GUNTHER, 2000).

Nem sempre as pessoas têm o conhecimento dos danos ambientais que podem estar relacionados a objetos simples do seu cotidiano, e é preciso trabalhar com os estudantes de modo dialógico e não somente com monólogos por parte dos professores. É possível, desta maneira, formar a consciência, a responsabilidade e trabalhar incentivos para que as pessoas sejam disseminadoras desse conhecimento para que possamos evitar danos ambientais maiores à sociedade causados pelo descarte incorreto de pilhas e baterias que podem gerar a poluição ambiental. Considerando os componentes curriculares, essa é também uma oportunidade de se trabalhar o conhecimento de uma forma plural e, de certo modo, minimizar as barreiras impostas pelas ementas disciplinares.

Pode-se e deve-se realizar trabalhos em relação ao lixo e materiais descartados de modo interdisciplinar e transdisciplinar. A interdisciplinaridade pode ser trabalhada por temas que permeiam entre os componentes curriculares (MELLO; DOMINGOS, INCROCI, 2014). No caso da transdisciplinaridade, esta não desvaloriza as competências disciplinares específicas, ao contrário, as eleva a níveis de conhecimento melhorados para os diferentes componentes envolvidos em diferentes áreas (ASSMANN, 1998).

As disciplinas, muitas vezes, são estanques, mas é possível realizar trabalhos que quebrem as barreiras disciplinares por meio de temas que exijam a busca de respostas em 
outros componentes curriculares. Este é o caso do trabalho com o lixo, os resíduos e materiais descartados de forma correta para minimizar os impactos ambientais (SHITSUKA et al., 2009). A conscientização começa pela formação de conceitos na mente das pessoas.

Nas linhas seguintes discorre-se sobre a aprendizagem dos conceitos sobre as questões ambientais.

\subsection{Aprendizagem sobre $o$ ambiente e a cidadania apoiada na autonomia e transdisciplinaridade}

Não adianta a sociedade tentar somente corrigir os problemas ambientais já existentes sem ter outras ações que garantam um futuro melhor. Torna-se interessante que se prepare as novas gerações para que elas prossigam nos trabalhos iniciados. Neste sentido, é preciso realizar um trabalho de educação ambiental envolvendo as questões de sustentabilidade e desenvolvimento sustentável. Enquanto aquela se refere ao fato de se buscar coisas duradouras e boas para a sociedade, e se relaciona com os processos para se alcançar a sustentabilidade (COUTINHO; SHITSUKA, 2011); o ensino das questões de preservação do ambiente para as gerações futuras e a própria existência dos indivíduos no Planeta torna-se uma questão também de cidadania, na qual todos sabem que possuem direitos e obrigações.

É importante também trabalhar os conceitos com indivíduos e grupos, pois muitos deles se formam nas trocas, de modo social (BARROS, 2013). À medida que os estudantes vão formando conceitos em suas mentes, podem se relacionar melhor com as questões importantes para o futuro da vida neste Planeta, e tais estudos são indicados para serem realizados em locais adequados para se ter um aprendizado de forma mais rápida, eficiente e eficaz.

Um dos locais mais interessantes para a realização dos trabalhos é na escola e por meio de projetos interdisciplinares que podem permitir o aprendizado com apoio das mídias e de modo autônomo (PRADO, 2003, SILVA; PINTO, 2009; TEIXEIRA, 2014).

Nos colégios, reúnem-se os atores relacionados ao ensino e a aprendizagem e também se juntam as condições para que ocorram os processos educacionais de modo adequado. $\mathrm{O}$ estudo escolar pode ser realizado com o apoio de pessoas e instituições externas, pesquisas de textos, imagens, vídeos, depoimentos e interações na internet em laboratórios de informática do colégio, para a formação dos conceitos importantes. 
Nos estudos os estudantes podem compreender, descobrir ou construir o conhecimento, através de novas formas de trabalho, e perspectivas para novos empregos, com uma atitude independente. Esta é uma forma de aprender em que se respeita o conhecimento já existente no estudante e sua velocidade de aprendizagem (FREIRE, 1996).

É possível realizar algum aprendizado nas igrejas, clubes, em ambientes familiares e de trabalho, porém a escola é um local onde se juntam pessoas de uma determinada faixa etária com a finalidade de realizar os processos educacionais e de ensinoaprendizagem. Nas escolas, para se ter a aprendizagem que respeite a velocidade de apropriação de conceitos e saberes pelos estudantes, é preciso que haja incentivo aos estudos de modo autônomo e por meio de projetos. Este tipo de abordagem difere do trabalho escolar tradicional, que é realizado somente por meio de aulas expositivas, que nem sempre são significativas para os estudantes.

Um dos fatores limitantes do aprendizado é o estudo por disciplinas que criam fronteiras ou limites de atuação. Para eliminar este impacto, faz-se importante a realização de reuniões com os envolvidos no projeto para se trabalhar a questão da transdisciplinaridade.

No trabalho transdisciplinar não existe hierarquização dos saberes e todos ficam no mesmo patamar (SANTOS, 2008). Pensa-se, então, em ir além das disciplinas e avançar mais no conhecimento coletivo. Para realizar um trabalho com essas características, é preciso considerar a existência da complexidade, como considera Morin (2001), e trabalhar com uma atitude de aceitar a vida e seus processos com curiosidade, reciprocidade e intuição para a detecção de possíveis relações entre fenômenos e eventos que não seriam vistas de outra forma (MORAES, 2010).

No trabalho com equipes com formações diferentes e objetivo comum, torna-se mais interessante ainda a abordagem transdisciplinar, de modo que as pessoas não trabalhem isoladamente ou buscando objetivos individuais.

Quando se pensa na educação por projetos, é interessante contar com um grupo de pessoas de diferentes áreas de atuação para poder apoiá-los e incentivá-los. Segundo Sebastian e Allenworth (2012), as pessoas com capacidade de liderança podem ajudar a viabilizar os projetos transdisciplinares.

Projeto é um conjunto de ações e atividades com objetivo comum e, para que suas ações e atividades ocorram, é preciso ter pessoas que incentivem seus colegas e pares a 
saírem da inércia e buscarem a participação e o alcance dos objetivos comuns do projeto. As linhas seguintes apresentam algumas formas de incentivo por meio da divulgação.

\subsection{Divulgação dos trabalhos e a aprendizagem sustentável}

O planejamento das ações em grupo para execução do trabalho e apresentação dos resultados em eventos é interessante como fator incentivador para o surgimento da motivação nos estudantes para a realização desses. Este é o caso da apresentação de trabalhos em eventos científicos que incluem encontros, simpósios, congressos e outros.

Um exemplo de evento importante, que ocorre a nível do país, é a Semana Nacional de Ciência e Tecnologia. Este é um evento anual e nacional voltado para disseminação e incentivo à Ciência e Tecnologia nas escolas da Educação Básica, o qual é incentivado pelo Conselho Nacional de Pesquisas (CNPq) e pelo Ministério da Ciência e Tecnologia (MCT). Já um tipo de evento local pode vir a ser o desenvolvimento de uma Feira de Ciências no Colégio. Geralmente, os estudantes ficam animados ao saberem que vão poder apresentar para seus pais ou parentes o resultado do trabalho que idealizaram e executaram.

A interação social e a emoção são importantes para que ocorra o aprendizado (WALLON, 2008). Há um aspecto da interação social, seja com os colegas, parentes ou membros da comunidade, que acaba estimulando os jovens na realização do projeto.

Além do estímulo ao trabalho fornecido pelos docentes, os estudantes devem motivar seus colegas para a sua realização. A motivação pode ser através de uso das mídias e da internet em pesquisas relacionadas ao tema principal proposto. Os computadores e a internet permitem aos estudantes superarem as dificuldades da distância e do tempo em relação às pesquisas, tais como visitas a museus, a outras escolas e, o mais importante, a busca de melhores informações (HEIDE; STILBORN, 2000).

O uso das mídias, seja televisiva, DVD, jornais, revistas e, principalmente, as mídias do nosso tempo que estão convergindo para a internet, podem ser úteis neste processo de aprendizado. Os meios podem servir como organizadores do aprendizado de novos conceitos. Estes são previstos na Teoria da Aprendizagem Significativa (AUSUBEL; NOVAK; HANESIAN, 1980; SHITSUKA; SILVEIRA; SHITSUKA, 2011).

O uso de organizadores prévios pode servir como incentivador, estímulo ou fomento para o surgimento da motivação para o aprendizado e o prosseguimento na 
realização do projeto. E os aprendizados de conceitos e saberes, que ocorre com os enfoques mencionados, tendem a ser duradouros e a fazerem sentido na vida dos estudantes, que não vão esquecê-los com facilidade. Tais conhecimentos vão acompanhálos por muitos anos e, desta forma, pode-se dizer que se tornarão "sustentáveis".

\section{METODOLOGIA}

Uma pesquisa pode ser realizada associada a um projeto de pesquisa. Os projetos e a investigação são importantes para a formação dos estudantes de modo interdisciplinar. As pessoas podem aprender de modo significativo por meio da pesquisa científica ou de projetos de pesquisa (AUSUBEL; NOVAK; HANESIAN, 1980, CASTRO, 2008, SHITSUKA; MORCELLE, 2014).

Quando o ensino define condições conjuntas, envolvendo o estudante na definição de objetivos, prazos, formas de trabalho, pontos de controle ou de alcance de resultados parciais e totais, pode-se fornecer alguma autonomia aos estudantes, que desta forma não estarão completamente perdidos. $\mathrm{O}$ trabalho qualitativo realizado na pesquisa pode ser quantificado por meio de escalas de conversão para se obter algum valor quantitativo, como é o caso do estudo empregando escalas Likert. A ideia é avaliar o conhecimento anterior à realização do projeto nos estudantes por meio de entrevistas e questionários com questões abertas e outras seguindo a escala Likert.

A escala Likert é um tipo de escala na qual se faz uso de questionários de múltipla escolha e uma alternativa a selecionar. Em cada questão se faz uma afirmação e as alternativas representam os graus de concordância em relação à afirmação. Em geral trabalha-se com cinco alternativas onde 1 é a mais discordante e 5, a mais concordante (VIEIRA; DALMORO, 2008).

A execução do projeto consistiu na realização de trabalhos de coleta de pilhas e baterias em uma escola no Município de Itabira; no desenvolvimento de experimentos voltados para demonstrar a importância da logística reversa e a necessidade com relação à coleta e à reciclagem de materiais; e na realização de apresentações em eventos que ocorreram na escola e no campus da Universidade.

No desenvolvimento das ações envolvidas no projeto, trabalhou-se de modo transdisciplinar, inicialmente por meio de pesquisas no laboratório de informática onde os professores de ciências, português, desenho, geografia, educação física e artes acompanharam os estudantes nas fases de pesquisa e de levantamento de informações 
para o projeto, as quais foram realizadas no laboratório de informática em que todos trabalharam em conjunto, quebrando barreiras relacionadas ao fato de serem de disciplinas diferentes.

A fase final do projeto consistiu na avaliação dos conceitos adquiridos pelos estudantes que passaram pelo projeto por meio das questões que seguiam a Escala Likert.

O presente estudo foi realizado com a participação de professores e de cinco estudantes da Universidade Federal de Itajubá - Campus Itabira, num trabalho conjunto com professores das disciplinas de ciências, matemática, português, história e geografia e suas respectivas turmas da educação básica do $6^{\circ}$ ano ao $9^{\circ}$ ano, contando, ainda, com a participação de voluntários e de cerca de 96 estudantes de uma escola pública localizada na região sudeste.

Por respeito às questões éticas e em respeito ao pedido dos professores, evitou-se citar nomes dos profissionais e estudantes envolvidos no trabalho.

\section{RESULTADO E DISCUSSÃO}

\subsection{O desenvolvimento das atividades e os resultados e discussões}

Inicialmente, os professores e estudantes da universidade fizeram um trabalho de sensibilização dos discentes da escola, passando em todas as salas do período da manhã e apresentando vídeos mostrando o funcionamento de uma pilha de limão; falando também sobre a questão da poluição associada aos geradores elétricos químicos.

Durante as apresentações iniciais, fez-se o convite para os estudantes visitarem os laboratórios da universidade onde eles aprenderiam a pesquisar vídeos, imagens, textos e sites sobre a questão da poluição relacionada aos geradores elétricos químicos, do impacto ambiental e da forma correta de se realizar o descarte. No laboratório de informática que contava com 50 máquinas, o professor mostrava aos estudantes como realizar pesquisas na internet. Muitos deles nunca tinham realizado uma pesquisa científica e consideravam que a internet era importante só para se comunicar nas redes sociais. Todos eles ficaram maravilhados ao observar os objetos e vídeos disponíveis na rede.

Numa etapa seguinte, os professores e os universitários receberam os estudantes da escola em turmas de cerca de vinte e cinco (25) elementos cada, que vieram acompanhados sempre de uma coordenadora, uma ou duas docentes e uma assistente. Por parte da universidade havia sempre um ou mais professores e pelo menos um ou dois 
estudantes para apoiar o trabalho de pesquisa. A Figura 1 apresenta uma imagem de estudantes da rede municipal visitando o campus avançado de Itabira.

Figura 1 - Visita de estudantes da rede municipal à UNIFEI, campus Itabira

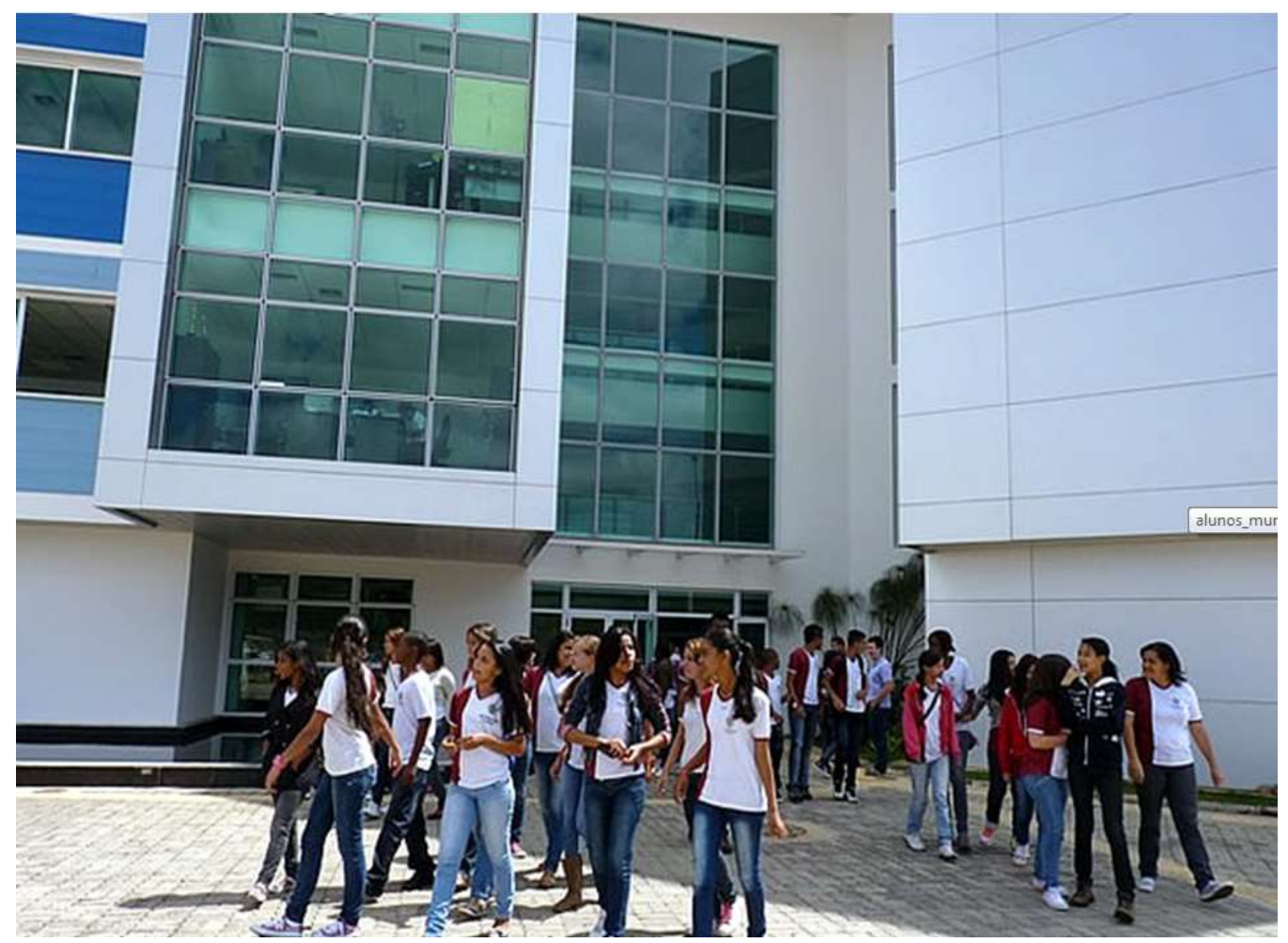

Fonte: http://www.viacomercial.com.br/2012/10/alunos-da-rede-municipal-visitam-campus-daunifeiitabira/

Algumas declarações comuns a vários estudantes foram agrupadas, fazendo-se a categorização por tipo, nas quais se observou a existência de regularidade para se constituir o corpus da pesquisa:

Declaração tipo 1: "Eu não sabia que dá para aprender tanta coisa no computador. Antes eu só usava para jogos."

Os estudantes da educação básica dos tempos atuais são considerados como sendo "nativos digitais", pois já nasceram em ambientes cercados por tecnologia como é o caso dos celulares, DVDs, micro-ondas, computadores, tablets, dentre outros. (PRENSKY, 2001). Porém, o fato de os estudantes terem facilidade no uso desses equipamentos não quer dizer que os utilize bem, ou seja, no sentido de aproveitar suas potencialidades para o aprendizado. 
Os estudantes na medida em que aprendem a utilizar melhor os recursos tecnológicos também ficam mais motivados e isso caminha no sentido de adquirirem uma sabedoria no uso dos recursos digitais (PRENSKY, 2009). A sabedoria digital consiste não apenas em ter os recursos, mas também em desenvolver habilidades e competências e em saber utilizá-los de forma a apoiar o sucesso nos estudos e no aprendizado.

Declaração tipo 2: "eu estou gostando, eu encontrei muita coisa sobre a poluição das pilhas e baterias."

Como já abordado, o desenvolvimento de habilidades faz com que os estudantes passem a utilizar melhor os equipamentos. Com as imagens, os vídeos e os resumos, os estudantes passam a contar com organizadores prévios, como consideram Ausubel, Novak e Hanesian (1980), que são autores desenvolvedores da teoria da aprendizagem significativa, e Shitsuka, Silveira e Shitsuka (2011), que exemplificam a aplicação desta forma de aprendizagem e que irão formar conceitos iniciais. Estes conceitos irão servir para que as novas informações relacionadas se ancorem e para que se formem novos conceitos de modo que os estudantes aprendam significativamente; e este pode ser um dos motivos pelos quais eles se interessaram tanto pelas mídias. Outra possibilidade é que havia muitos aprendizes visuais e a observação das imagens trouxe os incentivos necessários para ocorrer a aprendizagem.

Declaração tipo 3: “Gostei de trabalhar com muitos amigos da escola e a gente descobriu muitas coisas na internet."

Verifica-se pela declaração que os estudantes desta categoria consideraram o trabalho com interação social importante para sua motivação e aprendizado. Tais interações neste caso vão ao encontro de Wallon (2008), que considera importante a afetividade por meio do diálogo e a interação entre os envolvidos no processo de aprendizagem que ocorre socialmente.

Declaração tipo 4: “A gente gostou de sair da sala de aula."

A questão de sair da sala de aula se encontra num contexto no qual a sala é onde são trabalhadas as disciplinas. Quando se saiu da sala e se visitou o laboratório de 
informática da universidade e, por meio deste, se acessou a internet, os estudantes tiveram a oportunidade de viajar para outros lugares.

As questões ambientais, de sustentabilidade e de desenvolvimento sustentável envolvem o conhecimento de diversas áreas de modo interdisciplinar. O projeto contribui para a disseminação da ciência e tecnologia, para a formação interdisciplinar de cidadãos, e para o conhecimento em relação ao aprendizado significativo.

A apresentação dos trabalhos na feira de ciências que aconteceu na escola e que foi associada à Semana Nacional de Ciência e Tecnologia (SNCT) trouxe para o campus da UNIFEI várias pessoas da comunidade do entorno, que incluíam, entre outros, parentes, vizinhos e amigos dos envolvidos nos projetos. Os estudantes elaboraram folders de publicidade, que foram impressos e distribuídos na comunidade, nos quais se fazia a orientação para o descarte correto das pilhas e baterias. Foram feitos postos de coletas e experiências.

O trabalho orientado para educação ambiental ocorre com certa periodicidade (conforme o calendário escolar) nas escolas de educação básica para se formar pessoas conscientes, cidadãs, responsáveis e atuantes na sociedade, no sentido de se fazer com que todos trabalhem para alcançar a sustentabilidade.

A maioria dos estudantes declarou-se motivada e feliz por realizar o trabalho com os colegas, tendo aprendido muito, além de pedir aos docentes da universidade que voltassem sempre para realizarem mais projetos na escola. Também vários estudantes declararam que queriam estudar na universidade e se tornarem docentes na área de ciências.

\section{CONSIDERAÇÕES FINAIS}

Existem produtos e objetos importantes para atender às necessidades das pessoas e da sociedade, mas que, uma vez descartados de forma inadequada, podem trazer prejuízos ao meio ambiente e à saúde das pessoas. Este é o caso das pilhas e baterias usadas nos eletroeletrônicos.

As pilhas e baterias fornecem energia móvel de baixo custo e alta durabilidade, porém possuem metais tóxicos em sua constituição que comprometem a saúde humana e geram impacto ambiental. No Brasil a Resolução CONAMA 401 de 2008 estabelece os limites máximos de metais tóxicos em pilhas e baterias. 
A educação ambiental e a conscientização em relação ao uso e descarte correto de pilhas e baterias para se minimizar os problemas ambientais neste projeto envolveu o trabalho interdisciplinar e transdisciplinar em uma escola municipal de educação básica de nível fundamental.

O projeto interdisciplinar trabalhado contribuiu para que os estudantes adquirissem mais conhecimento; permitiu a eles trabalharem com autonomia e numa velocidade ou possibilidade de aprendizagem significativa.

O uso de laboratórios de informática com internet permitiu aos estudantes acesso a informações sobre museus, institutos de pesquisa, outras escolas, sobre as ciências e outros projetos de modo a encontrar subsídios para a realização, a divulgação e a interação, facilitando o aprendizado.

A divulgação e exposição de resultados pelos estudantes se mostrou um fator incentivador em suas próprias motivações para o alcance dos resultados.

Os autores consideram que o trabalho realizado serviu de incentivo para que muitos estudantes sigam carreiras relacionadas ao ensino de ciências.

Sugere-se, para trabalhos futuros, que se pesquise e se desenvolva outros projetos transdisciplinares, como o apresentado neste trabalho, para estudantes da educação básica. O intuito é que eles continuem motivados a prosseguir em seus estudos e se tornem docentes e profissionais das áreas de ciências e matemática.

\section{REFERÊNCIAS}

ASSMANN, H. Reencantar a Educação: rumo à sociedade aprendente. 4.ed. Petrópolis: Rio de Janeiro. Editora Vozes, 1998.

AUSUBEL; D. P.; NOVAK, J. D.; HANESIAN, H. Psicologia da aprendizagem. Rio de Janeiro: Interamericana, 1980.

BARROS, J. D. Sobre o uso de conceitos nas ciências humanas e sociais - uma contribuição ao ensino de Metodologia. Publicado em 2013. Disponível em: $<$ http://www1.sp.senac.br/hotsites/blogs/revistainiciacao/wpcontent/uploads/2013/07/6-art.pdf>. Acessado em: 30 out. 2019.

BERNARDES, T. O.; IACHEL, G.; SCALVI, R. M. F. Metodologias para o ensino de Astronomia e Física através da construção de telescópios. Caderno Brasileiro de Ensino de Física, v. 25, n. 1, p. 103-117, 2008.

CASSIANI, S.; LINSINGEN, I.; GIRALDI, P. M. Histórias de leituras: produzindo sentidos sobre ciência e tecnologia. Pro-Posições, Campinas, v. 22, n. 1, abr. 2011. 
CASTRO, V. A pedagogia por projetos como estratégia para formação de professores para o uso do computador na educação. Dissertação (Mestrado) apresentada ao programa de Pós-Graduação em Educação da Universidade de Brasília. 2008.

CONAMA. Resolução Conama ${ }^{\circ}$ 401, de 4 de novembro de 2008 Publicada no DOU n 215 , de 5 de novembro de 2008, Seção 1, página 108-109.

FREIRE, P. Pedagogia da autonomia. São Paulo: Paz e Terra, 1996.

FREITAS, D. R. Extensão na Educação Superior. Revista Interação Interdisciplinar (ISSN: 2526-9550), v. 3, n. 1, 2019.

GUIMARÃES, S. E. R.; BZUNECK, J. A.; SANCHES, S. F. Psicologia educacional nos cursos de licenciatura: a motivação dos estudantes. Psicologia Escolar e Educacional, v. 6 , n. 1, p. 11-19, 2002.

GONÇALO, M.I.P.; Sousa, A.; ANDRADE, J.C. Programa de extensão horto didático: instrumento para introduzir a alfabetização cientifica na escola. Corixo-Revista de Extensão Universitária, n. 7, 2019.

HELDE, A.; STILBORNE, L. Guia do professor para internet: completo e fácil. Porto Alegre: Artmed, 2000.

MARCUZZO, S. et al. Estratégias para motivar a aprendizagem da embriologia: um relato de experiência no curso de enfermagem da Universidade Federal do Rio Grande do Sul. Revista Internacional de Educação Superior, v. 5, p. e019011-e019011, 2019.

MELlO, A., DOMINGOS, B., INCROCCI, L. O processo de construção de uma pesquisa interdisciplinar: simetria e conceitos nômades. Revista Brasileira de Gestão e Desenvolvimento Regional, América do Norte, 10, set. 2014.

MORAES, M. C. Transdisciplinaridade e educação. Rhisome Freirean. V.6, 2010. Publicado pelo Instituto Paulo Freire de Espanha. Disponível em: $<$ http://www.rizomafreireano.org/index.php/transdisciplinaridade-e-educacao--maria-candida-moraes $>$.

Acesso em: 30 out. 2019.

PAULA, E. C.; SHITSUKA, R. Avaliação das noções de sustentabilidade em três cursos de engenharia. ENCICLOPÉDIA BIOSFERA, Centro Científico Conhecer - Goiânia, v. 7, n.13, p. 1084-1092. 2011. Disponível em: $<$ http://www.conhecer.org.br/enciclop/2011b/ciencias\%20ambientais/avaliacao\%20das $\% 20$ nocoes.pdf $>$. Acesso em: 30 out. 2019.

PINTO, M. T. L. S.; FERREIRA, S. M. M. Práticas transdisciplinares na seção de ensino do Colégio Militar de Salvador. RICAM Revista Interdisciplinar de Ciências Aplicadas à Atividade Militar, v. 1, n. 1, p. 60-77, 2019.

PRADO, M. E. B. B. Pedagogia de projetos: fundamentos e implicações. Série "Pedagogia de Projetos e Integração de Mídias" - Programa Salto para o Futuro, setembro, 
2003.

Disponível

em:

$<$

www.eadconsultoria.com.br/matapoio/biblioteca/textos_pdf/texto18.pdf $>$. Acesso em: 30 out. 2019 .

REIDLER, N. M. V. R.; GUNTHER, W. M. R. Gerenciamento de resíduos constituídos por pilhas e baterias usadas. In: XXVII Congresso Interamericano de Engenharia Sanitária e Ambiental. ABES. Pontifícia Universidade Católica do Rio Grande do Sul (PUCRS), de 3 a 8 de dezembro de 2000.

RODRIGUES, Maria Lucia. Caminhos da transdisciplinaridade-fugindo a injunções lineares. Serv Soc Soc, v. 64, n. 1, p. 124-34, 2000.

RUIZ, M. R.; CHRISTOFOLETTI, R. A.; RUIZ, L. I. R.; Da SILVA, E. L. Desafios para o gerenciamento de pilhas e baterias pós-uso: proposição de projeto de lei sobre o e-lixo na cidade de Rio Claro-SP. Revista de Gestão Ambiental e da Sustentabilidade.v.1(2), p.32(21), 2012.

SANTOS, A. Complexidade e transdisciplinaridade em educação: cinco princípios para resgatar o elo perdido. Revista Brasileira de Educação. v. 13 n. 37 jan./abr. 2008.

SANTOS, Tonie Maria Gregory dos et al. Experimentação pedagógica no processo de aprendência: uma interconexão tecnológica, transdisciplinar e transversal. 2019.

SCHWARTZ, S. Motivação para ensinar e aprender: teoria e prática. Editora Vozes Limitada, 2019.

SEBASTIAN, J. E.; ALLENSWORTH, E. The Influence of principal leadership on classroom instruction and Student Learning: a study of mediated pathways to learning. Educational Administration Quarterly, v. 48, n. 4, p. 626-663, 2012.

SHIBAO, F. Y.; MOORI, R. G.; SANTOS, M. R. A logística reversa e a sustentabilidade empresarial. In: XIII SEMEAD - Seminários de Administração. 2010. ISSN: 2177-3866.

SHITSUKA, R. et al. Educação ambiental e a conscientização da sociedade no tratamento do lixo. ENCICLOPÉDIA BIOSFERA. v. 5, n. 8. 2009. Disponível em: $<$ http://www.conhecer.org.br/enciclop/20098.htm>. Acesso em: 22 nov. 2014.

SHITSUKA, R.; SILVEIRA, I. F.; SHITSUKA, D. M. Organizadores Prévios na Aprendizagem de Conceitos de Matemática num Curso de Engenharia. Linguagem Acadêmica, Batatais, v. 1, n. 1, p. 173-192, jan./jun. 2011.

SHITSUKA, R.; MORCELLE, V. A. Estrategias para la Divulgación de la Ciencia: Un Estudio de Caso de la Enseñanza con Lámparas Fluorescentes en Educación Básica. Revista Dialogos de la Comunicación. Felafacs. n. 88, 2014. Disponível em: $<\mathrm{http}$ ://dialogosfelafacs.net/estrategias-para-la-divulgacion-de-la-ciencia-un-estudio-decaso-de-la-ensenanza-con-lamparas-fluorescentes-en-educacion-basica/> . Acesso em: 30 out. 2019. 
SILVA, L. H. O.; PINTO, F. N. P. Interdisciplinaridade: as práticas possíveis. Revista Querubim - revista eletrônica de trabalhos científicos - Letras, Ciências Humanas e Ciências Sociais. ISSN 1809-3264 Ano 5. 2009.

TEIXEIRA, R. L. P. A escola cidadã: a avaliação formativa como ferramenta transformadora para uma escola cidadã. Maestria-Revista do Centro Universitário de Sete Lagoas, v. 1, n. 11, p. 135-143, 2014.

VIANNA, M. Interesse por cursos na área de Ciências diminui entre jovens. Publicado no website Ciencia e Cultura em 2014. Disponível em: $<\underline{\text { http://www.cienciaecultura.ufba.br/agenciadenoticias/noticias/interesse-por-cursos-na- }}$ area-de-ciencias-diminui-entre-jovens-2/>. Acesso em: 30 out. 2019.

VIEIRA, K. M.; DALMORO, M. Dilemas na construção de escalas tipo Likert: o número de itens e a disposição influenciam nos resultados? In: XXII Encontro da ANPAD. Rio de Janeiro, 06 a 10 de setembro de 2008.

WALLON, H. Do ato ao pensamento. Petrópolis: Vozes, 2008.

WEBER, M. A.; VIEIRA, F. C. B. Formação de professores para o ensino de solos: uma experiência com discentes do curso de Ciências Biológicas-Licenciatura. Revista Internacional de Formação de Professores, v. 3, n. 24, p. 127-144, 2019.

WEIL, P. Rumo à nova transdisciplinaridade. Summus Editorial, 1993. 